\title{
Recent Advances in Forest Pest Management: Unity in diversity
}

\author{
Peter de Groot \\ Forestry Canada, Forest Pest Management Institute, Box 490, Sault Ste. Marie, Ontario, P6A 5M7
}

\section{Introduction}

Typically, a mental image of forest pest management produces a scene of an aircraft spraying above the forest in the spring. It is unlikely, however, that the autumn scene reproduced on the cover of this issue of The Forestry Chronicle would engender an image of forest pest management, but there is no reason why it shouldn't. If we as forest managers want to portray good forest management as it really is, we must ensure that the forest users realize that forest pest management produces healthy forests, in the winter, spring, summer, and autumn. In addition, the cover picture shows diversity in forest composition. Diversity is also reflected in the principles and practice of pest management. As we mentally unite the richness in plant and animal species diversity and call it a forest, so too do we unite the diversity of tools and methods to practice forest pest management. Good forest pest management clearly embodies the notion that there is unity in diversity.

Practising foresters must be responsive and adaptive to the changing needs of society, and to the technological and scientific advances in many different fields. They must also be able to face the challenges that different public and corporate interests, knowledge, and perceptions present. To do this, they must be informed. The need for information is particularly evident in forest pest management, where there is increasing public concern about what foresters are doing in, and to, their forests.

During the autumn of 1990, the Canadian Institute of Forestry/Institut Forestier du Canada held a symposium entitled "Recent Advances in Pest Management" in Sault Ste. Marie, Ontario. The purpose of the symposium was to provide practising foresters, and those involved in the management of forest pests, an overview of different facets of pest management. The speakers were asked to highlight the progress in research and development in their fields, and to speculate and emphasize how these advances are, or will become, part of the forest management process. Many of these papers are presented here; the remaining papers will appear in the next issue of the Forestry Chronicle.

I thank the Canadian Institute of Forestry and the organizing committee for their hard work in bringing the symposium together, the sponsors who helped pay for the symposium meeting and the costs of publishing these proceedings, and the editors and reviewers for their comments and reviews of the manuscripts.
Symposium organized under the auspices of the Canadian Institute of Forestry/Institut forestier du Canada.

Co-sponsored by Forestry Canada, Canadian Pulp and Paper Association, Ontario Ministry of Natural Resources and The Central Ontario Section of The Canadian Institute of Forestry.
Planning Committee
P. de Groot (Chair)
E. Caldwell
C. Krishka
J.-P. Martel
G. Munro
F. Ortiz
J. Wainwright

\author{
Financial Assistance \\ Abbott Laboratories \\ Chemagro Limited \\ Dow Elanco Canada Ltd. \\ Monsanto Canada Ltd. \\ Sumitomo Chemical America, Inc.
}

